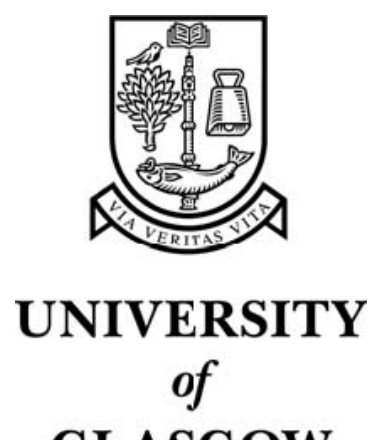

GLASGOW

Galani, A. and Chalmers, M. (2004) Production of pace as collaborative activity. In, Conference on Human Factors in Computing Systems, 24-29 April 2004, pages pp. 1417-1420, Vienna.

http://eprints.gla.ac.uk/3449/ 


\title{
Production of Pace as a Collaborative Activity
}

\author{
Areti Galani, Matthew Chalmers \\ Dept. of Computing Science \\ University of Glasgow, UK \\ areti@dcs.gla.ac.uk, matthew@dcs.gla.ac.uk
}

\begin{abstract}
In this paper we investigate the concept of pace development and management among groups of people. We explore and compare groups visiting museums, and groups virtually co-located in a mixed reality system for a museum. In considering pace, and how to design to support it, we have to consider more than the speed or location of information display. We have to also take into consideration the social formation of pace through features such as the visitors' awareness of each other's location and attention. By considering aspects of collaboratively produced pace such as presenting engagement and disengagement, we offer suggestions as to how social handling of pace might be better supported by technology.
\end{abstract}

\section{Author Keywords}

Pace, Mixed Reality Environments, Location Awareness, Visitor Studies, Museums, CSCW.

\section{ACM Classification Keywords}

H.5.1 Multimedia Information Systems, and H.5.3 Group and Organization Interfaces

\section{INTRODUCTION}

In recent years, the demand for personalisation of the user experience and the technological push from new hardware developments have led to the research and development of personal mobile devices that offer access to information on the move. These devices are increasingly directed towards leisure activities such as tourism, sightseeing and museum visiting. Commercial products such as audioguides and map tools have become more widespread, and research work continues to explore new possibilities for information display [5, 9] and social interaction around such information $[1,3]$.

Researchers and developers often make indirect claims of supporting exploration of information at the individual user's pace, although pace itself has not often been discussed explicitly, with [6] being a notable exception. The social management or handling of the pace of interaction also arises indirectly in studies of collaboration and collaborative systems, and it would seem that the collaborative production and handling of pace is an important aspect of the overall user experience, but relatively little has been published that focuses on pace in detail, especially with regard to how groups handle the combination of their interaction around artifacts and displays, and their interaction with each other.

Pace is commonly defined as the manner of stepping or running, as well as the speed or rate of progress. It refers to movement within geometric or geographic space as well as the rate of accomplishing an activity such as speaking or reading. When pace is used to describe movement through space it also carries a sense of directionality or directedness, hence progress toward a goal. One's pace is also influenced by time constraints and features of the environment, such as terrain, crowds, mode of transport and so forth.

Although, individuals may have their own pace in accomplishing an activity, there are many situations where social aspects of pace are also important, and each individual's pace is affected by and affects others'. This is a common part of everyday life when people walk with their friends on the street, go shopping together or visit an exhibition. Groups of people often take part in sporting activities such as hillwalking, cycling and horseriding, and clubs often organise 'social pace' events [4], i.e. excursions that are done in a relaxed manner "with plenty of opportunities to smell the roses, view the scenery, and stop at bakeries or other refreshment locations". These events are meant to appeal to a variety of members and offer the opportunity for socialising as well as exercising, with the promise that "nobody will be dropped or left alone".

Audio guides in museums are often used for pace management purposes so people who listen to the commentaries do not crowd up in front of a display but move evenly around the exhibition. Specifically in well attended 'blockbuster' exhibitions, the audio commentaries are designed to impose both a certain speed as well as direction to visitors, prompting them to move on along a route. On the other hand, research in wearable computers and digital tourist guides [10] utilised accelerometers to infer one's activity from one's pace, for example whether the user is sitting, running etc., so as to make available 
appropriate information. In group situations, pace has been associated with coordination, for example in studies of tourists [3], hunters [11], and mobile game players [8]. Coordination among group members is often done explicitly via talk, e.g. via mobile phones, and also via awareness of location, as may be supported by systems for location tracking and display, e.g. active badges and media spaces [7], Hummingbird [15], and MR systems [2].

In this paper we look beyond coordination, and consider its relationship to individual attention and self-presentation. We look at visibility, pausability and embodied interaction, drawing examples from visiting activity among collocated and non-collocated museum visitors. We draw examples from a visitor study in two cultural institutions and a study of a MR system that supported the simultaneous shared exploration of a gallery by a group of visitors who were not collocated. Reflecting on these issues and on the way that current technologies use and support pace, we put forward issues and suggestions for future system designs intended to better fit and support the shared visit experience.

\section{PACING THE VISIT}

The pace of the visit is an essential aspect of shared museum visits. Each individual's pace influences the overall pace of the group as well as the quality of the experience, since each individual operates as a filter for her friends. Pace in museums is not related only to moving through a space but also to moving through information, for example reading labels. In studies of how people walk together [12], the participants in the activity seemed to formulate in advance the "problems of direction, pace, destination etc., that can be potentially problematic". Museum visitors, instead, tend to adapt a more exploratory attitude - especially when the pace and the direction of the visit are not predefined due to limited visiting time or because of following a guided tour. In collaborative production of visiting pace, each member contributes to the overall direction and speed of the visit by negotiating engagement with the exhibition with other members. This negotiation is an intrinsic, 'unremarkable', part of the overall visiting activity and to some extent, characterises the leisure aspect of the museum experience. However, it is more consciously and explicitly handled upon in cases of coordination, for example when a member of the group needs to leave the exhibition space and visit the restrooms.

\section{Visibility and location awareness}

In our observations of visitors we found that members of a group adjusted their pace in order to stay in the relative proximity of each other or at least in visual contact with their companions. The spatial features of the gallery played an important role in this procedure. For example members of the same group in the House for an Art Lover (HAL), effectively a historic house, tended to stay within the same room, so they could easily locate their friends by just looking around even if they were engaged in separate explorations of different artifacts. Therefore, visual accessibility functioned as a straightforward location awareness mechanism to support collaborative production of pace throughout the visit and, effectively, more regular interaction among friends. On the other hand, in Mackintosh Interpretation Centre (Mack Room), an exhibition and information space, visual contact throughout the gallery was disrupted by the displays, so visitors were 'forced' to actively search for their friends in the room, some times at the expense of their personal engagement with the displays.

In our study of non-collocated visitors, in the Mack Room, the members of the group were also offered a location awareness mechanism: a map and a virtual environment with representations of themselves and their friends which were constantly updated according to visitor's movements. They were also offered an open audio channel. An extended description of this system and the studies can be found in [2]. The analysis of the study showed that despite some problems with coordination, people were able to locate each other and use location as an effective resource for their engagement with the displays and the overall collaboration.

We noticed however that the production of pace was not 'unremarkable'. Instead, the participants often engaged in explicit negotiations and interactions to achieve and sustain it. We note here three of these 'remarkable' behaviours:

- Verbal expression of participants' intentions to move and description of where to go next (Excerpt 1).

- Explicit choice to move around and about displays they could mutually share (Excerpt 2).

- Questioning of unpredicted movements (Excerpt 3).

In the excerpts, $\mathrm{L}$ is the local visitor, and $\mathrm{R} 1$ and $\mathrm{R} 2$ are remote visitors. Square [brackets] show overlapping talk/action.

\section{Excerpt 1}

L: Ok, I am wandering.

$R$ : Are you? Where are you wandering off then?

L: Ehmmm... other side of the room.

Excerpt 2

$R$ : What are you looking at now?

L: Ehm, I am going to go around and have a look at the Timeline, I think, cause it might be easier to... to keep up. $R$ : Ok, alright, let's go there.

Excerpt 3

L: Jo (R1), where... you've gone out to the [Reception] for some reason?

$R 2$ :

[Jumps to

Reception point on the map]

R1: I just haven't been here before

L:Hah

In many instances of the trials the participants were observed to switch from 'doing visiting' to describing how they might do visiting. They were effectively pulled away from visiting and called to account for it as Tolmie et. al. [14] put it. This perceived disruption in pace highlights that 
location information and verbal communication were not sufficient resources for unproblematic production of pace during the short time of the trial visit by relatively novice users. In the next subsections we discuss two additional aspects in the production of pace, that of self-presentation and that of embodied action.

\section{Accountable pauses}

The role of the pause in people's interaction has been discussed in conversational analysis with regard to turn-toturn discussion/negotiation [13]. The timing and the length of the pause have the dual role: to emphasise completion of an activity and to give time for the collocutor to respond. In our observations museum visitors used 'gestural pauses' to indicate that they had finished with the exploration of one object and they were ready to move on. The pause was usually expressed in both time and space, as physical removal from the object of previous engagement, for example a step backwards, to indicate disengagement from the activity in hand. This effectively visual cue supported one's companions' awareness of one's current status and implicitly communicated one's intention to move.
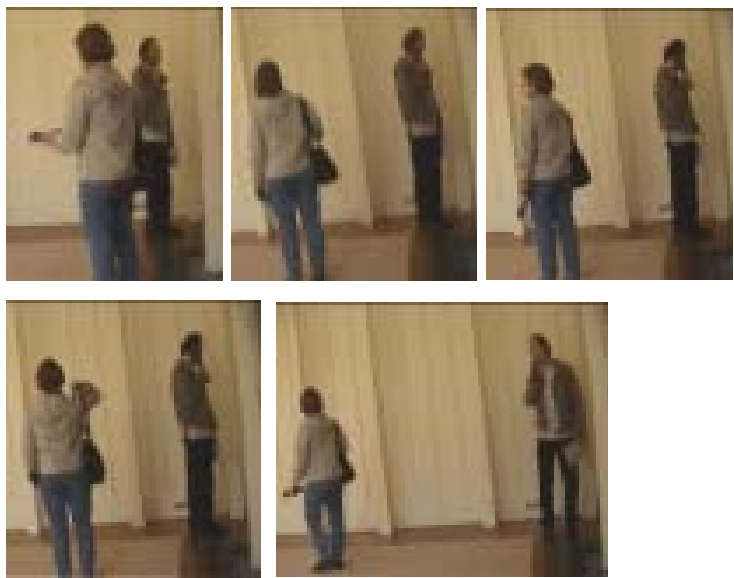

Figures 1-5, A couple, visitors in HAL

The couple in figures 1-5 was listening to the audio commentary about the fireplace in the Music Room, in HAL. A few seconds later, the woman decided to stop her commentary (see Figure 1) and move on, but instead of directly moving away, she took some steps away from the fireplace and stood there for several seconds looking leisurely around and adjusting her bag (see Figures 2-4). It was only when she started walking away that her companion turned towards her (see Figure 5). The woman's pause was what we could call an 'accountable' action; effectively a movement that the woman made in order to present herself as ready to move on.

Self presentation appears as an important aspect of establishing collaborative pace, since it offers to participants the necessary cues to become aware of each other's intentions. Furthermore a pace-specific element of self presentation is how one presents one's self at different stages of engagement/disengagement with an activity. In the above example for instance, the woman's pause indicated an overall disengagement of her previous personal activity of attending the fireplace but only a 'light' disengagement of the shared activity of exploring the room together with her companion. In this case, the production of shared pace was the result of implicit negotiation between the two visitors and a compromise among their individual engagement with the exhibition. We believe, however, that it increased their experience of being together and consequently offered more opportunities for exchange and interaction later in the other side of the room.

\section{Embodied pace management}

In the last section we saw how self presentation may inform the production of pace. In the following example we observe how explicit gestural behaviour might implicitly inform change of pace. We also remark that handling of engagement and disengagement does not necessarily involve identifiable discrete parts, like in the earlier example, but the boundaries might be blurred with social interaction.
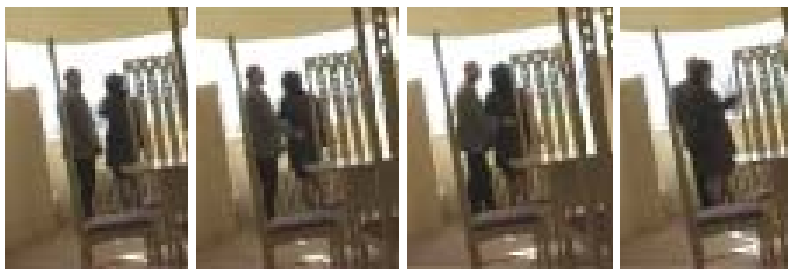

Figures 6-9, A couple, visitors in HAL

In the excerpt both visitors were discussing the view from the window using gestures (see Figure 6) for emphasis. In the following two images (see Figures 7-8), the man on the left, whose orientation was perpendicular to that of the woman, took the woman by her waist and slowly twisted her towards the other direction. The pace of the movement and its smooth, 'intimate' character permitted the woman to slowly disengage of the previous interest and re-engage with a new one as it is indicated by the fact that she seamlessly started pointing at another object (see Figure 9) within her new field of view, the fireplace.

Subtle social gestures, like the man's gesture in our example, are often used in the negotiation of pace among companions. They usually communicate one's intentions to move along not as individual but as a group. Therefore, the companions' implicit or explicit agreement is necessary for the achievement of the move, like the woman in the example, who accepts the gesture follows the move.

\section{DISCUSSION}

In this paper so far we looked at the ways pace is collaboratively produced during a museum visit. We also discussed our experience from a mixed reality museum environment that primarily supported collaborative production of pace through location and gesture awareness, and verbal communication. In our observations of museum 
visitors we found out that self-presentation plays an important role in the collaborative production of pace, as one indicates the various degrees of engagement with an activity and one's own intentions to move on.

With existing technologies for such shared visits, it may be difficult to engage with information about a location or artifact, while also indicating via location or gesture that one is ready to move on from that artifact. Similarly, it may be difficult to use a tool for the display of information about a location or artifact without losing awareness of others' movement and gesture. Simple avatars and map icons often lack the subtlety of expression required to produce the necessary implicit cues for shared pace.

It may then be that the design of systems for such shared visits should take this dual presentation into account, either by dual displays or regions of a display. Alternatively, one might use multiple media so that one tool or medium shows detail of an artifact or location, while another tool or medium that lets one see/hear what is going on with other artifacts and locations. An example is the use of spatialised audio to show the direction/distance/talk of co-visitors, while one focuses on some very detailed graphics. Similarly, audio display of information can be complemented by a graphical map that affords enough peripheral awareness of others to let one decide when to move on. Additionally, members of a group could be digitally tied together, hence have the opportunity to mark objects, or produce markers, so as to attract their friends, or even to explicitly other's fields of view.

This short paper only started addressing the issues behind collaborative production of pace in leisure group activities. Two strands of future investigation would be possible: the first to further compare pace production among users in the physical space and users in a VE and among the former and users of a hypermedia environment; the second, to further examine the role of collaborative production of pace in the sense of presence and togetherness and whether this aspect of togetherness is worth pursuing in a mixed reality environment. Hopefully, we will come back on that soon.

\section{CONCLUSION}

We believe that as more applications move towards the support of collaborative leisure activities, support of pace will become an important element of smooth and enjoyable shared experiences. In this paper we drew examples from a museum visiting experience among collocated and noncollocated visitors to discuss location awareness and visibility as resources of pace production. We also argued that those resources need to be coupled with effective selfpresentation and expression of various degrees of engagement to support the collaborative production of pace ace and enhance the shared experience.

\section{ACKNOWLEDGEMENTS}

The authors thank B. Brown and E. Laurier for discussions on the issues of this paper. They also thank all the members of the City project, past and present, and the staff and visitors of The Lighthouse and the House for an Art Lover. This work was part of the Equator IRC, which is funded buy UK EPSRC, and was assisted by a donation from Hewlett-Packard.

\section{REFERENCES}

1. Aoki, P. M., Grinter, R. E., Hurst, A., Szymanski, M. H., Thornton, J. D., and Woodruff, A. Sotto Voce: Exploring the interplay of conversation and mobile audio spaces. Proc. CHI 2002, ACM Press, 431-438.

2. Brown, B., MacColl, I., Chalmers, M., Galani, A., Randell, C., and Steed, A. Lessons from The Lighthouse: Collaboration in a shared mixed reality system. Proc. of CHI 2003, ACM Press, 577-584.

3. Brown, B. and Chalmers, M. Tourism and mobile technology. Proc. of ECSCW 2003, Klewer Academic Press (2003), 335-355.

4. Capital Bicycle Club Saturday Social Rides 2003, http://www.capitalbicycleclub.org/cbcsocialrides2003.p df

5. Cheverst, K., et al. Developing a context-aware electronic tourist guide: Some issues and experiences. Proc. of CHI 2000, ACM Press (2000), 17-24.

6. Dix, A. Pace and interaction. Proc. of HCI'92, Cambridge University Press (1992), 193-207.

7. Dourish, P., and Bly, S. Portholes: Supporting Awareness in a Distributed Work Group. Proc. of CHI 1992, ACM Press (1992), 541-458.

8. Flintham M., Anastasi R., Benford, S., et. al. Where online meets on-the-streets: Experiences with mobile mixed reality games. Proc. of CHI 2003, ACM Press (2003), 569-576.

9. Marti, P. Design for art and leisure. Proc. of ICHIM 2001, Archives \& Museum Informatics (2001), 387-397.

10.Randell, C. and Muller, The well mannered wearable computer. Personal and Ubiquitous Computing 6, 1 (2002), 31-36

11.Rikard H. Exploring the concept of group interaction through action in a mobile context. Proc. of DEXA 2002, Springer-Verlag (2002), 567-576.

12.Ryane, L.A. and Schenkein, J.N. Notes on the art of walking. Ethnomethodology: Selected Readings. Penguin Education, New York, 1974.

13.Sacks, H., Lectures on conversation: Vol. I \& II. Blackwell, 1998.

14.Tolmie, P., Pycock, J., Diggins, T., MacLean, A., Karsenty, A. Unremarkable computing. Proc. of CHI 2002, CHI Letters 1(1), 399-406.

15.Weilenmann, A. Negotiating use: making sense of mobile technology. Personal and Ubiquitous Computing 5, 2 (2001), 137-145. 